\title{
Analyzing online search patterns of music festival tourists
}

\author{
Juan D. Montoro-Pons ${ }^{1}$ \\ Manuel Cuadrado-García ${ }^{2}$ \\ ${ }^{1}$ Departamento de Economía Aplicada, Universitat de València, Spain. \\ Email: juan.d.montoro@uv.es \\ ${ }^{2}$ Departamento de Comercialización e Investigación de Mercados, Universitat de València, Spain. \\ Email: manuel.cuadrado@uv.es
}

August 7, 2020

\begin{abstract}
Music festivals as cultural events that induce tourism flows intermediate both the cultural and travel experience. The present study analyzes online search behavior of potential attenders to a music festival. We hypothesize that the search process reveals latent patterns of behavior of cultural tourists planning to attend music festivals. To this end, information from Google Trends on queries related to three popular music festivals are used to build a network of search topics. Based on it, alternative exponential random graph model specifications are estimated. Findings support the general result of mediated information flows: music festivals induce planning and traveling queries. However differences relating to the specificities of the cultural event are also found, in particular those regarding what nodes or queries supply the network with more useful information.
\end{abstract}

Keywords: cultural tourism, cultural consumption, music festivals, web searches, exponential random graphs models, user-generated data 


\section{Introduction}

The increasing relevance of music festivals as cultural events where audiences experience live music has had a twofold impact. Firstly, in the music industry, where curating and bundling cultural content combined with the spatial and temporal concentration of the supply of live music has emerged as a successful business model. Secondly, in tourismrelated services, through the linkages and spillovers from cultural engagement into those activities that enable such participation. In short, music festivals illustrate a type of cultural tourism where cultural participation induces tourism flows. To some extent music festivals are themselves a tourist destination.

In both cases, music as cultural participation and tourism, consumers face informational problems related to the experiential nature of these activities, which only after consumption can be assessed. Asymmetries of information and unknown quality lead to uncertainty and consumption risks that challenge consumers and affects the extent of their engagement with cultural or touristic activities and, therefore, that of the underlying markets. In such cases online information can be one way of reducing associated risks as it becomes an imperfect substitute for the actual experience (Bei et al. 2004).

The present study analyzes online search behavior about cultural events that, we assume, mediate the process of information acquisition. We use the digital footprint that Internet users generate when searching information about music festivals and propose these are informative and complementary to other standard empirical techniques. The dataset of googled terms we use can be interpreted as a set of manifest variables about underlying behavioral patterns of cultural tourists planning to attend music festivals.

Specifically, we posit that related search topics (i.e. terms queried in the same online search session) and the links they form pinpoint the mediating function that certain cultural events serve in cultural and touristic markets. By looking at what is searched, the existing links between queries, and the (in)existence of indirect means to connect two disjointed search terms, we are able to describe the search space of cultural tourists, the process through which searches are associated and how both enable discovery. In short, this paper analyzes the online information gathering that cultural events trigger and how it is related to the formation of the choice set of the cultural tourist. Methodologically, we follow a quantitative case study approach (Eisenhardt and Graebner 2007) and use a novel approach that equates the process of planning cultural participation to a directed graph.

We collect information on online search activity for three reputed popular music festivals in Spain. The dataset identifies the different aspects that are related to the cultural tourist decision-making, from obtaining basic information about the event to planning at- 
tendance, traveling and leisure activities. We process it using a graph layout (topics are nodes and links connect topics that are searched together) and estimate the underlying structure that channels the information acquisition of cultural consumers when planning attendance to a live music event. In so doing we aim at characterizing what factors act as facilitators of the diffusion of information through the observed graph of search terms, and how these reflect consumer behavior. All this to be understood in a framework where actual behavior is preceded by motivation or intention (Ajzen 1991).

Findings provide evidence of rational addiction and voracity, as well as of spillovers and linkages into other related activities, mainly those related with travel. We also find evidence of the hierarchical structure of search topics, which reinforces the notion of information acquisition as a mechanism that cultural tourists use as a means to reduce risk and uncertainty. Hierarchies of search topics are pinpointed through a core of connected nodes - those supplying the graph with relevant or authoritative information along with others that enable its diffusion - and less accessible peripheral search topics. Furthermore, there are differences across events and the geographical scope of searches, which can be associated to alternative behavioral patterns.

The main contribution of this research is related to the fields of cultural tourism, cultural mediation theories, and theories of asymmetric information in cultural consumption. Drawing on these, we quantitatively show the relevance music festivals have in channeling information gathering that ultimately helps consumer discovery and market creation. This research, in short, is an analysis on mediated information flows in cultural markets that produce informational spillovers. Additionally, we contribute to the literature on cultural tourism by the use of a non-standard dataset and a novel methodology that, to the best of our knowledge, has not been applied before. ${ }^{1}$

The paper is organized as follows. First, a brief and general background on cultural tourism and its relation to cultural events and the festivalization of culture is introduced. Here, we include a discussion on the mediated information acquisition that cultural events trigger, which is contextualized within the information search and planning literature in the field of tourism economics and management. Second, an exploration of the dataset, the data gathering process, and the formation and classification of the basic units of analysis (nodes and edges of a network of search terms) and its structure and graphical description are introduced. Then statistical models for graphs (exponential random graph models) and testable hypotheses are laid out, followed by the estimation results. The paper concludes

\footnotetext{
${ }^{1}$ Abbruzzo et al. (2014) use a network to identify the determinants of tourism expenditure. Nevertheless, their methodology and application significantly differs to the proposed in this paper.
} 
with a discussion of the main findings.

\section{Background}

Music festivals influence cultural and tourism participation decisions through a combination of (i) selection, curation and bundling - producing and distributing a temporary cultural resource - and (ii) the geographical concentration of cultural content. As a result, festivals trigger consumers' information acquisition directed towards the reduction of risk and uncertainty that enables cultural tourists' discovery and decision-making. To analyze the search patterns this process activates, first we outline the nature of cultural tourism and discuss the mediating role certain market institutions, such as music festivals, serve.

\subsection{Festivals and cultural tourism}

As cultural tourism sits at the intersection of two activities any definition implicitly singles out what drives behavior: cultural participation or tourism. Noonan and Rizzo (2017) point out that cultural tourism can be summarized as the analysis of the interconnections between cultural participation and tourism organization and how the former affects the emergence of specific tourism patterns.

Bonet (2013) takes a more restrictive viewpoint when pinpointing that, as most tourists engage in the consumption of goods and services with some cultural component, one should look at what motivates consumers to differentiate cultural tourism from other traveling experiences. In short, the relevant distinction lies on whether culture is the main drive of the touristic experience or just accessory to it, and the role that cultural supply plays in explaining tourism.

From this perspective, the evidence shows an association between tourism flows and cultural resources (Borowiecki and Castiglione 2014), even though the direction of causality is far from settled. Research supports both: cultural resources induce tourism (Cuccia et al. 2016; Guccio et al. 2017) and vice versa (Cellini and Cuccia 2013). In this respect, observed behavior could reflect the heterogeneity of motivations of tourists, which ranges from pure cultural engagement to a more recreational attitude towards culture (Brida et al. 2016).

The foregoing discussion highlights the demand-side of cultural tourism, where intrinsic cultural motivations explain decision-making. However it neglects the market creation role of specific institutions such as festivals, which stand out as an urban planning strategy to attract tourism through cultural consumption. The term festivalization describes the increasing relevance of festivals as a medium for cultural consumption. From a policy 
standpoint, festivalization has been considered as a strategy that structures and organizes leisure and cultural activities and that helps in the re-framing of urban spaces (KarpińskaKrakowiak et al. 2009). Festivals can be seen as a policy tool that relies on cultural events to market cities - a potential driver of success in the positioning of cities - but that exceed the framework and objectives of city marketing (Hitters 2007; Richards 2007).

The supply of temporally- and geographically-constrained cultural resources has been shown to potentially attract tourism flows (Gergaud and Ginsburgh 2017; Vecco and Srakar 2017), a market creation effect that is mediated by the differential motivations that local audiences and tourists exhibit (Faulkner et al. 1999; Herrero et al. 2012; Báez-Montenegro and Devesa-Fernández 2017). All in all, as festivals enter the choice set of cultural consumers, decisions unrelated to those of cultural participation emerge as a byproduct.

\subsection{Mediated information acquisition}

Although the literature has singled out the potential of cultural events as tourism facilitators, it has overlooked how this function is performed. Cultural consumption draws heavily on actors that select, signal and legitimate cultural artifacts and in so doing, promote consumer awareness of the cultural supply and facilitate consumers' search and discovery (Janssen and Verboord 2015). In short, cultural markets rely on organizations, such as music festivals, that induce market creation (Hiller 2016).

Two aspects are noteworthy vis-à-vis festivals. First, when attendance is mostly driven by the cultural event, i.e. culturally motivated, the flow of non-local audiences can be described as a prototypical instance of pure cultural tourism: the cultural activity is to be seen as the main reason for traveling and not just as a complementary activity to be undertaken at destination.

Second, as a consequence, festivals not only influence cultural consumption decisions but also tourists' decision making. In this respect, music festivals serve a mediating function that spills over the tourism experience, helping cultural tourists to reduce perceived risk and uncertainty. Information collection and planning are part of the decision-making process tourists undertake. In this respect, by restricting the search space of cultural tourists - a process we define as mediated information acquisition - festivals induce the dissemination of information and reduce consumers' search costs. In short, festivals shape the search mechanisms that drive cultural tourists' decision making.

Search, information collection and planning as part of consumers' decision-making process are central topics in the tourism literature. Research around these issues has highlighted, among others, the impact of information and communication technologies, how 
widespread they are, and their uses.

For consumers, the use of digital technologies has reduced costs and facilitated access to information, although it has dramatically increased the complexity in decision-making with the number of choices users face (Buhalis and Law 2008). Note that, as the complexity of consumers' choices escalates, the value to consumers of actors that restrict and mediate the search space, hence simplifying decision-making, also increases.

Users rely on different online tools in order to acquire information and simplify the planning of the travel experience (Chung and Buhalis 2009; Casaló et al. 2010). While these have been found to be widespread across all customer segments, there is some variability in the use of particular resources, such as social media, and the utility derived from and weight placed on them (Xiang et al. 2015; Llodrà-Riera et al. 2015). The planning process has been conceptualized through the sources, search patterns and dimensions of the search process, the activities involved in each of the steps, and the role that the different travelrelated technologies play at each step and towards the experience satisfaction (Pan and Fesenmaier 2006; Papathanassis and Knolle 2011; Ho et al. 2012; Huang et al. 2017).

In this regard, a central topic is that of travel planning as a strategy to deal with uncertainty and risk. How is risk assessed and its influence on search behavior have been found to have a potential mediating effect in the information search process at the planning stage of the travel (Björk and Kauppinen-Räisänen 2015). In this context, risk is associated to the choice of information sources: when planning traveling, the higher the risk perception the more likely travelers move beyond informal information sources, which on the other hand could enhance the role of organizations or actors involved in the process.

Moreover, and from the supply side, technologies that provide consumers with information at the planning stage of the tourism experience could be potentially cost-effective means of marketing destinations (Litvin et al. 2008; Cox et al. 2009; María Munar 2011; Pan and Li 2011). To put it differently, from the organizations' perspective, inducing and disseminating information about a destination (or a cultural event for that matter) could raise participation.

To sum up, as collecting information is central in tourism decision making, the specific actors that help disseminate that information influence market outcomes. Cultural tourists embed travel planning, search and information gathering within cultural attendance, which changes the decision-making framework. Against this background, we aim at identifying the structural mediating role music festivals play in the diffusion of information and how they influence consumers' choice set through the search processes they bring about. 


\section{The dataset}

The empirical research is based on a quantitative analysis of the Internet search terms (and the relations between them) googled by potential attenders to three music festivals in Spain. The increasing access to online user-generated content has not only enlarged the toolset of empirical research but also shifted its focus (Artola et al. 2015; Blazquez and Domenech 2018; Jun et al. 2018). In the case of cultural participation, where behavioral complexity can be challenging, it allows to obtain valuable information from individuals that might not be elicited with more standard techniques such as surveys (see Scuderi and Dalle Nogare 2018; Stephens-Davidowitz 2014).

\subsection{Selection of cultural events}

Theaudience share of large music festivals has been rising in Spain in the past few years (SGAE 2018). From 5\% of the total attendance of popular music performances in 2008, it jumped to over $21 \%$ in 2017. Furthermore, large festivals represent in 2017 over 50\% of total income in the sector, up from $20 \%$ in 2008. Interestingly, these figures are at best a lower bound for income and attendance as they refer to a handful of festivals classified as large events. Altogether, data show an increasing concentration in live music led by music festivals. This paper analyzes online search activity around three renowned live music events in Spain.

The festivals included in the sample meet two criteria: (i) they attract a significant share of non-local audiences (such that these qualify as cultural tourists); and (ii) generate enough online search activity. Given these constraints, a natural choice is large music live events: table 1 lists the top ten music festivals in Spain using data available from the website of the Spanish association for music promoters (http://www.apmusicales.com), which ranks festivals by attendance. While this list includes a heterogeneity of live events, two aspects are worth mentioning.

First, the ranking shows a mix of long standing reputed festivals, such as Festival Internacional de Benicassim (FIB) or Sónar, along with newcomers such as Arenal Sound and Medusa Sunbeach (both set up in the 2010s). As the purpose of this research is to identify cultural consumer traits that emerge from online searches, we need to constrain the variability of consumer uncertainty to that related to planning attendance and (maybe) the lineup, and not to the quality of the event itself. Established festivals are therefore a natural choice: they have an accumulated reputation that is reflected on its brand, that provides valuable information about cultural supply for consumers. 
Second, festivals in table 1 can be classified, in general terms, across two dimensions: location and lineup proposal. As for the former, two groups can be identified: those that take place in a urban environment (Primavera Sound and Sónar in Barcelona, and Mad Cool in Madrid) and those that are held in a rural location (rest of the festivals in table 1). It is noteworthy that with one exception (Viña Rock), all of the latter take place in seaside resorts, which reinforces the link of festivals to touristic destinations.

The lineup proposal produces a more heterogeneous classification of live events. However, by looking at how broad is the scope of the music genres festivals portray, one could identify two types. On the one hand, niche or specialized festivals such as Sónar (with an experimental/electronic/avant-garde focus) or Rototom (a reggae music festival). On the other hand, festivals that have a more general appeal by including in their lineup a wide array of music genres. Here one can include festivals such as Primavera Sound or $F I B$, which, although generally classified as alternative rock festivals, have actively pushed their boundaries by enlarging the scope of genres in its lineup to include urban music and hip-hop along with the more expected mix of rock, pop and R\&B.

Taking everything into consideration, three festivals are selected: FIB, Primavera Sound and Sónar. These are reputed festivals that portray a mix of location (urban/beach resort) and genres (specialized/broader appeal). Furthermore, the selected events rank on top vis-à-vis the share of non-domestic audiences they attract. Using figures from the official report of the music promoters association (APM 2018), FIB, Primavera Sound and Sónar are the only three music festivals in Spain whose share of non-domestic attenders exceeds $50 \%$. This choice, allows us to identify general search patterns emerging from large established music festivals that attract significant flows of tourists, but also differential ones based on location and genres.

\subsection{Data gathering}

To collect the dataset, we use data from Google Trends (GT) on queries most frequently performed when searching for web information on the three music festivals selected. GT main functionality is that of providing an index of the volume of queries of any given web search term in a particular geography. Internet search indexes have been widely used in tourism economics to improve the predictive power of time series models. Particularly, the literature abounds with applications of web search indexes to predict inflows of tourists (Artola et al. 2015; Bangwayo-Skeete and Skeete 2015; Padhi and Pati 2017; Yang et al. 2015; Bokelmann and Lessmann 2019).

We draw on the complementary information that GT provides in relation to a search 
query. Particularly, we make use of top searches: these are terms most frequently queried along with the term entered in the same search session, within the chosen category and country (or region). By using top searches we produce a database of terms that were most frequently queried along with the festivals we analyze by Google users. This is performed individually for each one of the three events. Furthermore, two geographies are selected: world searches and searches performed in Spain. Overall, we produce a database of search terms across three events and two geographies.

Data gathering was automated through the use of an application programming interface (API) for Google Trends ${ }^{2}$. The data collection proceeded in a stepwise fashion. First, the initial or entry search terms - FIB, Primavera Sound ad Sónar - were disambiguated using the suggestions functionality of GT. It allows us to unambiguously select only those queries that refer to the festival name. This is relevant as running a query for a search term like Sónar, returns several results each one with a unique code identifying its meaning. Among them one finds: \{'Sonar'; 'Topic'\}, \{'Sonar'; 'Mobile application'\} and \{'Sónar';'Music Festival'\}. In this case only top searches emerging from the latter are of interest. We performed this procedure on the three search terms (FIB, Primavera Sound, Sónar) selecting the codes that uniquely identify each music festival.

Second, for each search term we collect the list of top searches. Note this list is contingent on the geography of the searches (world and Spain) and the time period considered. As for the latter, table 2 shows the details of the search. All search queries collected span from (roughly) when the (preliminary) lineup is officially announced (around the end of January in all three cases) until the festival ends. The reason for the starting date is apparent: as a festival announces its lineup it starts to generate buzz around it and (we infer) online activity. It should be noted that this produces a somewhat longer time period for FIB as it takes place later in the year (mid/end July). Furthermore, this time period queries is split into five equal time intervals. Then, top searches are retrieved for each query term given the geography and time interval.

To find cross-links between top searches (or back-links to the festival search term) we proceed one step further by looking at top search terms related to those found in the first stage. We retain only information on searches that are linked to any of the initial search (festival) or top searches in the first round. As a result we gather a dataset composed of search keywords and the connections between them. Let a graph $N$ be defined as a collection of nodes $V$, and the ties between them $L$, i.e. $N=(V, L)$. Then, the dataset of

\footnotetext{
${ }^{2}$ https://github.com/GeneralMills/pytrends. Alternatively, there is a R package, gTrendsR that offers similar functionalities.
} 
festival-related searches can be represented as a directed graph, in which nodes are search terms and edges appear when a node is in the list of top searches of another node. ${ }^{3}$

The resulting graph shows queried terms and connections between them as cultural consumers gather information surrounding a cultural event when planning attendance. It also describes the scope of interests that emerge as potential attendees search about and become aware of the cultural supply surrounding a music festival. This process is assumed to have an impact in terms of market creation as it defines the choice set of consumers planning to attend a cultural event.

\subsection{Classification of nodes}

While the dataset itself has been transformed into a structured graph, information about the content of the searches (the specific queries users make) are textual and, as such unstructured. To process this information, nodes have been classified into seven categories according to the query they refer to. By looking at categories we reduce the inherent complexity of the analysis and are able to model and quantify the patterns that emerge within and between these categories.

After revising all the queries produced by each node retrieved, the following categories are considered: (i) music festivals (a category that includes not only the festivals analyzed but other related festivals individuals search for); (ii) event planning (here we include all the information surrounding the festival, such as lineup, ticketing, stages or locations of venues among others); (iii) travel and travel-planning searches (accounts for information including airlines, accommodation, currency, language and geographical searches such as cities or countries); (iv) music and musicians (including queries that refer to performers, albums, genres etc.); (v) leisure activities (mainly searches for cultural activities and cultural institutions, sports and sport events, and nightlife); (vi) media (those queries involving traditional and online media); and (vii) miscellanea as a residual category.

Table 3 shows the cross-tabulation of category of the search nodes and music festival. A breakdown for the geographical scope of searches has been included, showing the relevance of some categories (e.g. travel) when considering the intention to attend.

The full list of nodes (or search terms) for the events are listed in appendix A. For each node the table includes full name of the query (node label), the topic in which GT classifies it (Google classification), and the category we assign to each node. From it, it becomes apparent that a small fraction of all search terms are indeed unrelated to the events under

\footnotetext{
${ }^{3}$ Let search terms A and B be in the node set: then an edge from A to B is defined if B is in the list of top searches of A.
} 
consideration. These nodes could be seen as noise (most likely mistakes while entering a search term) that anyhow we retain in the dataset.

\subsection{Structure and description of the dataset}

After processing the raw data using software tools (Butts 2008) the resulting networks of search terms are displayed in figures 1 to 6 . We use the category label to identify each node to simplify the display and interpretation of the dataset. Furthermore, the size of each node and its label are proportional to its centrality in the graph. Centrality measures summarize the prominence, importance or popularity of the different nodes (search terms) in the graph. We use authority centrality, whose rationale goes as follows: a node is important when it contains valuable content and hence receives links from other important nodes; conversely, nodes with fewer incoming links have low centrality. Authority centrality measures the extent to which nodes contain relevant information and thus are reached by other nodes that either contain valuable information themselves or facilitate (bridge) connections.

Three findings are evident from the graphical inspection. Firstly, in all cases graphs contain a core of densely connected nodes and a periphery of (relatively) isolated end points. Furthermore, search terms that refer to music festivals are over-represented in this core. This suggests that, in planning participation, live music consumers include and consider a diversity of cultural events in their choice set.

Secondly, and not unexpectedly, gathering travel information (planning the trip by searching about the country/region/city, how to reach there, and where to stay) has a differentiated role depending on the geographical scope of the search. When considering searches from all over the world, and from the perspective of their centrality in the network, traveling comes second in importance to festivals. On the contrary, searches within Spain give prominence to other search categories, such as collecting practical information about the event (planning) or about the musicians in the lineup.

Thirdly, the distribution of the importance or popularity of the different search terms seems to depend on the scope of the festival. Recall that a node's centrality is given by its size. Then, the distribution of centrality is more egalitarian in the more specialized event (figures 5 and 6) than in the two festivals with a broader appeal (figures 1 to 4 ). This suggests patterns of Internet information acquisition that exhibit a more hierarchical structure for FIB and Primavera Sound - fewer nodes are relevant sources of information in the search process - compared with the more egalitarian distribution of the prominence of nodes for Sónar — where most nodes carry equally valuable information.

Nevertheless, we should note that the complexity of the relations emerging between 
nodes makes the graphical representation of a network of limited value when it comes to obtain additional information about its structural properties and how these influence the formation of edges. To do so, we propose a statistical model to make inference on the emergence of patterns in graphs.

\section{Methods}

Next, we discuss the empirical approach that allows to analyzes the determinants of the emergence of links or edges between the nodes (i.e. search terms) in the network. The statistical analysis produces two applied results. Firstly, it allows us to identify the function that the explicit structural properties of the network serve in triggering consumer planning and discovery patterns. Secondly, and based on the different structural properties of the three cases undertaken, it pinpoints the differential traits in information search of potential attenders to different cultural events.

\subsection{Exponential random graph models}

The empirical analysis draws on a probabilistic representation of graphs, where observed edges are one realization of a random variable. Define a graph $N=(V, L)$, and denote $\mathbf{Y}$ as its adjacency matrix. Let $Y$ be a random variable such that

$$
Y_{i j}= \begin{cases}0 & \text { there is no tie from } i \text { to } j \\ 1 & \text { there is a tie from } i \text { to } j\end{cases}
$$

Let $\mathbf{y}$ be a realization of this random variable. Then, an exponential random graph model (ERGM) defines the probability of observing a specific network as

$$
P(\mathbf{Y}=\mathbf{y})=\frac{\exp \left\{\eta^{t} g(\mathbf{y}, \mathbf{X})\right\}}{\kappa(\eta)}
$$

where $g(\mathbf{y}, \mathbf{X})$ represents any possible network statistic, which depends on structural features of the network as well as covariates $(\mathbf{X})$ describing node or link properties that are hypothesized to affect the probability of this network forming; $\eta$ represents the parameters defining the formation of ties, and $\kappa(\eta)$ is a normalizing constant that ensures probability adds up to one. The goal is to obtain maximum likelihood estimators (MLE) for the parameter vector $\eta$ from the observed network $\mathbf{y}$. This implies using Markov chain Monte Carlo (MCMC) maximum likelihood estimation for models in which edge formation processes are endogenous (the case under consideration). 


\subsection{Covariates}

To estimate an ERGM for the network of search terms we specify $g(\mathbf{y}, \mathbf{X})$ in expression (1) to include measures of the structure of the network and nodal and dyad-related covariates. These account for the heterogeneity in the formation of ties due to node, interaction and structural effects.

Node effects determine the sociality or propensity of nodes to form links with other nodes. This propensity is measured through the degree or popularity of the node (i.e. search term). Note that, as the graph is directed, degree has multiple meanings: outdegree or number of edges originating from a given node; in-degree or number of edges incident to it; and total degree as the sum of both. These are grouped by category of nodes in order to produce a meaningful interpretation of the effect of search topics within a category on the structure of the graph. When possible, in order to measure how a particular category increases or decreases the odds of the formation of an outgoing/incoming edge, two terms will be included for each node category. However, in some specifications, due to the sparseness of the resulting graph, total degree is used.

Interaction effects identify the tendency of two nodes to form an edge based on some measure of proximity. The underlying notion is that of nodes clustering together according to their similarity or dissimilarity. Here one distinguishes between assortative mixing or homophily, when links tend to emerge between similar nodes, and dissortative mixing or heterophily, when dissimilarity between nodes induces the formation of ties.

We use a node's category to determine the existence of either homophily or heterophily in the web-search patterns of cultural consumers. Assortative mixing or homophily occurs when nodes in a search category tend to cluster and be segregated from nodes within other categories. If this is the case, reaching a node or search term within the category increases the likelihood of it leading to other searches within the same category, increasing the depth of the information acquisition on that topic. Heterophily, on the other hand, implies a search category creating spillovers on other categories, expanding the breadth of the information acquisition. Consequently, the model includes the inclination of nodes within categories to form ties with similar/dissimilar nodes.

Structural properties of the graph are also incorporated in the model. First, we include a measure of the density of the network as a function of a homogenous edge probability (the control variable edges, analogous to the intercept in a linear regression) and a term for the reciprocity of ties, mutual. Second, an expanded measure of transitivity is also included through the geometrically weighted edgewise partner distribution (gwesp), which accounts for the tendency of two nodes that share partner(s) to be also connected. If positive, 
increasing the number of shared partners increases the likelihood of tie formation. However, link formation exhibits decreasing marginal returns to additional shared nodes. To some extent gwesp measures the effect of local clustering on the likelihood of the dissemination of ties. ${ }^{4}$

Table 4 lists all covariates. Note that the choice of covariates for the different models is determined by the convergence of the estimation process and/or model non-degeneracy.

Finally, two models were estimated: (i) a time-collapsed model in which all ties formed within the sampling period are included regardless of the period(s) of time they are active; and (ii) a separable temporal exponential random graph models (STERGM), which explicitly model the dynamics of tie formation and persistence over time.

\subsection{Hypotheses}

Based on the proposed empirical model, a set of hypotheses in relation to the mechanism that drives connections between searches are formulated. The mechanism driving information acquisition is the observed outcome of festivals' mediation in cultural and tourism markets: it channels the dissemination of information and, in so doing, reduces uncertainty and perceived risk.

First, the central mediating role of music festivals is hypothesized. Mediation is observed through the centrality in the graph of web search activity.

Hypothesis 1 (H1): Festival-related searches induce link formation.

Second, we assume that risk and uncertainty of traveling to the festival increases for nonlocal audiences. Therefore, it should be reflected on the connectivity of traveling nodes which are expected to form more ties when the scope of searches is unrestricted (i.e. worldwide searches).

Hypothesis 2 (H2): Travel-related terms have a greater tendency to form links in worldwide searches.

Furthermore, interaction effects between searches are expected to emerge. In this respect, it is hypothesized that searches on music festivals spill over other search categories, facilitating discovery.

Hypothesis 3 (H3): Festival-related searches exhibit a bias in favor of connections with dissimilar network nodes. This effect broadens information acquisition.

\footnotetext{
${ }^{4}$ See Hunter and Handcock (2006) or Goodreau et al. (2009) for a discussion on these terms.
} 
As for searches within other categories, we expect them to be subordinated and lack expansiveness. To the contrary they are assumed to deepen information acquisition within the category. This case is expected to be relevant in the case of traveling and planning activities: reaching these nodes means that searches will be circumscribed to this domain, allowing users to intensify the information gathering on these particular subjects.

Hypothesis 4 (H4): Non-festival searches exhibit a bias in favor of connections with similar network nodes. This effect deepens information acquisition.

Finally, structural features such as the connectivity derived from clustering have an impact on how knowledge flows through the network, which, in turn, facilitates consumers' discovery process as nodes sharing partners will be very likely linked. In other words, indirect connections induce direct links.

Hypothesis 5 (H5): Network structures (local clusters) facilitate the dissemination of links.

\section{Results}

We estimate a static (ERGM) and dynamic (STERGM) specification for the different observed graphs. Results are provided in tables 5-7. Each specification includes covariates and the geographical scope of the searches analyzed (world and Spain). Estimates include standard errors and statistical significance, and coefficients are to be interpreted as the conditional log-odds ratio of a tie. In the static framework a positive (and significant) coefficient implies that the covariate increases the probability of an edge (a negative sign having the opposite interpretation). When time is explicitly considered, then two equations (one for tie formation and one for tie dissolution) are estimated for each graph, and coefficients reflect the probability of a tie forming or its persistence: a positive and significant coefficient increases the likelihood of tie-formation or its persistence over time.

To evaluate the qualityFirst, of the models two strategies have been undertaken. convergence of MCMC is achieved in all models: no correlation in the time pattern of the MCMC chain is apparent; moreover, histograms of the difference of observed and simulated sample statistics were roughly bell-shaped and centered at 0 . Next, estimated models have been used to simulate networks. Based on these simulations the $95 \%$ confidence interval for the degree distribution is produced and compared to the degree distribution of the observed network. Note that the goodness-of-fit of an ERGM is based on its ability to produce simulations whose distribution (for specific network statistics) include the values 
of the observed network. In our case cases only small parts of the degree distribution of the observed graphs sit outside the confidence-range bands provided by the models. This allows us to conclude with the adequacy of the estimated models.

\subsection{ERGMs estimation results}

Table 5 shows estimation results for the different static graphs. Structurally, ties are less likely than expected by chance (negative sign of edges) while reciprocity of ties is a feature of these graphs.

At the node level, we find search terms related to music festivals category tend to generate and attract more edges than those expected under a pure random process. Furthermore, intention to attend (gathering travel and event-specific information) affect information flows. Covariate node(io).Planning is found to be unambiguously related to incoming edges in every graph describing search behavior (negative impact on outgoing edges in model 3). As for node(io). Travel, estimates are consistent with alternative accounts of its impact, increasing the likelihood of incident links for the broader geographical scope (i.e. world searches) plus model (6); on the other hand the odds of a travel-related node being a sender of a link are substantially reduced for models (1) and (3) - unrestricted geographical searches for the two alternative rock festivals analyzed. Search terms classified as media were significant sender of edges in models (5) and (6), which could be related to the experimental and avant-garde nature of the event, where cultural mediation by specialized actors could prove to be relevant in consumer decision-making.

As for interaction effects, two findings emerge. First, when significant, estimates are negative for festival-related web searches, which supports dissortative mixing or heterophily for search terms within the festival category (models 1 to 4). Namely, festival-related searches tend to form edges with search terms within different categories, i.e. spill over, hence broadening the scope of queries.

Second, for other search categories segregation emerges: a tendency to link to searches within the same category. This is specially so for travel - models (1) to (5) - , which hints at individuals increasing the depth of the information on travel-related topics when planning for attendance. While similar findings emerge for other covariates, they appear to be less general as they are linked to specific events. In this regard, searches on music and musicians exhibit homophily in both festivals with a broader base models (1), (2) and (3). Likewise evidence supports assortative mixing of media-related searches in model (5). 


\subsection{Formation and persistence of links}

Tables 6-7 provide estimation results when the temporal dimension of searches is taken into account. A STERGM includes one equation for the formation and another for the dissolution of links. Positive and significant estimates in table 6 are interpreted as usual: they increase the probability of an edge formation. As for table 7 , positive coefficients are associated to factors that increase the persistence of an edge.

Starting with table 6, density effects are found to agree with those already discussed while reciprocity only drives tie formation when searches are restricted to Spain. This could point to the more hierarchical and structured search process of non-local audiences as compared to the bidirectional connections found in local ones. As for the impact of gwesp, it is found to be positive and significant. ${ }^{5}$ Therefore, local clustering increases the likelihood of link formation, helping to disseminate connections. This can be interpreted as the association of any two queries through the connections these share. Overall it broadens the scope of the information search and induces consumer discovery.

Evidence on node effects are consistent across events. Festival searches increase link formation in all models — but equation (6) - supporting the observed tendency of festivalrelated nodes to generate and/or receive more ties that expected. Collecting information about the event - node.Planning - drives tie formation in equations (1)-(2) and (5), although is non-significant in (3) and (4), which correspond to the most popular music festival analyzed. ${ }^{6}$ This finding is consistent with planning being more relevant the less known the event.

Fewer covariates affect the persistence of nodes (table 7). Structurally, local clusters tend to persist, given the positive and significant coefficient of gwesp in all equations. As for other covariates, only planning and traveling were found to increase link persistence in equations (3) and (4). Overall, it seems that once formed, the tendency of a tie to dissolve is mainly driven by its relative position in the network.

Overall, the empirical evidence supports most of the formulated hypotheses. Estimation results show that information acquisition is mediated through the analyzed events $(\mathbf{H 1})$. Both static and dynamic models point to a tendency of cultural events to produce spillovers in searches (H3), while planning and/or travel related information acquisition tend to deepen knowledge accumulation (H4). Moreover, the topology of online queries around music festivals favors the dissemination of queries (H5). However, the evidence in relation to $(\mathbf{H 2})$ is mixed: while the sociality of travel-related nodes is affected by geography in

\footnotetext{
${ }^{5}$ After after running the regressions with different values, the decay parameter is fixed at 1 in all models.

${ }^{6}$ By any measure in table 1 , but also in terms of the online activity it generates.
} 
table 5 , tables 6 and 7 provide inconclusive evidence.

\section{Discussion}

Cultural tourism is mostly about consuming experiences and information whose value is influenced by market intermediaries. These are actors that serve, among others, the purpose of spreading information across the market, a function that influences consumers' uncertainty, perceived risk and discovery. In live music, the tendency towards the temporal and geographical concentration of cultural supply, the so-called festivalization, has made a significant impact not only on what and how music is consumed, but also on the consumption of related services linked to the nature of these events, such as travel services.

The aim of this research is to provide an insight into an unexplored aspect of the intersection between cultural participation and tourism behavior as the outcome of a process of mediated information acquisition. Attendance to music festivals by non-locals is one instance of this type of consumer behavior. As potential tourists are culturally motivated, decision-making is mediated, and to some extent simplified, by the event they plan to participate in. This means that particular traits and patterns related to consumer behavior can be inferred from the process through which individuals collect information.

The research looks at the problem at stake through online searches stemming from three festivals. These searches are then modeled as a network, which emphasizes the mechanism that drives the diffusion of information. Which and how queries are connected and how this information spills over related queries are analyzed.

In this respect some results stand out. First, we find evidence of the voraciousness of live music consumption (see for instance Sullivan and Katz-Gerro 2006). Using a purely quantitative dimension of cultural consumption, voraciousness is equated with the scope of searches related to music festivals. Web based searches indicate that users spread the search over different music festivals, besides the one that triggered the search session. This includes not only franchises but also (domestic and foreign) competitors. The centrality of search terms within the festivals category and the fact that edges involving these nodes are more likely than predicted by chance is consistent with the addictive nature of cultural consumption as individuals include in their choice set an interest for a diversity of cultural events. We may infer that this interest (an antecedent of intention) stems from a disposition to attend.

Second, searches related to festivals facilitate information diffusion through two means. On the one hand, they have a tendency to create ties, i.e. they are central to the graph. 
On the other hand, they also show a propensity to mix with search terms within different search categories. This means that searches related to music festivals tend to spillover to searches within different domains, enlarging the scope of information acquisition. These are relevant in the case of planning attendance and traveling arrangements, which are central to cultural tourism. The estimated model suggests that the odds of online search leading to any of these two categories are larger than it would have been by pure chance. Festivals, driving online-search behavior, are actually mediating the process of information acquisition which stands as prior to decision-making. Note this finding is robust even when removing the node of the festival generating the network.

Third, other categories, specially planning and travel, either attract links from other searches or exhibit selective mixing. The former is related to certain nodes (planning) being reached due to their holding of relevant information about the event (e.g. ticketing or lineup). The latter stresses the need of individuals to deepen or complement information about a topic (in this case travel). When mixing occurs, the search is more likely to stay within the domain of the search term once it is reached, increasing the depth of the information acquisition. This finding reinforces the informational role of music festivals and the induced nature of information acquisition.

Fourth, graphs reveal differences across events and geographies. As for the former, two different patterns of information acquisition, potentially linked to differences in the degree of complexity and specialization of the analyzed events, emerge. Figures 1 to 4 describe a hierarchy of nodes in terms of the authority centrality displayed: while some nodes supply useful information to the network (those larger in shape), most contribute marginally. Conversely, figures 5 and 6 show an egalitarian structure where (almost) all nodes convey similarly relevant information. When no evident authoritative source of information exists, individuals should be expected to search across all sources (i.e.nodes) in the network with similar intensity, which leads to the observed egalitarian pattern. Furthermore, ERGMs estimates (table 5, models (5) and (6)) are consistent with the greater complexity associated to a niche event and consumers' need of specific cultural capital accumulated through specialized media when planning attendance to an avantgarde festival - i.e. Sónar — whose lineup shows a scarcity of headliners. ${ }^{7}$ This effect, however, has not been captured in the dynamic specification (STERGMs).

As for the geographical differences, world searches show a differential pattern: ERGMs estimates (table 5) provide evidence of travel queries generating more incoming links, while STERGMs (tables 6-7) suggest a greater likelihood of non-reciprocal ties. The evidence,

\footnotetext{
${ }^{7}$ The lineup can be inspected at https://sonar.es/es/2018/artistas-por-dias.
} 
while being partial, stresses the differential risk faced and the more structured approach - more focused search - of queries run by non-locals.

Overall, the foregoing discussion allows to identify patterns of behavior in tourist decision-planning across different dimensions. Besides differences emerging as a consequence of the specificities of the events considered, heterogeneity has been found in the relative position of search terms in the search space (which points to the relative relevance of the information that is searched), the likelihood and factors that influence the formation of links and the spillovers from the query on the cultural event generating the graph to other search terms, which determines the formation of the choice set of cultural tourists. To conclude, cultural tourists' behavior is reflected on the structure of the search graphs, where the centrality of festival nodes indicates culturally motivated planning and stresses the potential attracting role that such cultural events play. 


\section{References}

Abbruzzo, A., J. G. Brida, and R. Scuderi (2014). Determinants of individual tourist expenditure as a network: Empirical findings from Uruguay. Tourism Management 43, 36-45.

Ajzen, I. (1991). The theory of planned behavior. Organizational behavior and human decision processes 50(2), 179-211.

APM (2018). IX anuario de la música en vivo (IX Annual report of live music). http://www.apmusicales.com.

Artola, C., F. Pinto, and P. de Pedraza García (2015). Can internet searches forecast tourism inflows? International Journal of Manpower 36(1), 103-116.

Báez-Montenegro, A. and M. Devesa-Fernández (2017). Motivation, satisfaction and loyalty in the case of a film festival: differences between local and non-local participants. Journal of Cultural Economics 41(2), 173-195.

Bangwayo-Skeete, P. F. and R. W. Skeete (2015). Can google data improve the forecasting performance of tourist arrivals? mixed-data sampling approach. Tourism Management 46, 454-464.

Bei, L.-T., E. Y. Chen, and R. Widdows (2004). Consumers' online information search behavior and the phenomenon of search vs. experience products. Journal of Family and Economic Issues 25(4), 449-467.

Björk, P. and H. Kauppinen-Räisänen (2015). Contemporary insights to the dynamic pre-trip information sourcing behaviour. Tourism and Hospitality Research 15(1), 39-53.

Blazquez, D. and J. Domenech (2018). Big data sources and methods for social and economic analyses. Technological Forecasting and Social Change 130, 99-113.

Bokelmann, B. and S. Lessmann (2019). Spurious patterns in Google Trends data - An analysis of the effects on tourism demand forecasting in Germany. Tourism Management 75(May), 1-12.

Bonet, L. (2013, jan). Heritage tourism. In I. Rizzo and A. Mignosa (Eds.), Handbook on the Economics of Cultural Heritage, pp. 386-401. Edward Elgar Publishing Ltd.

Borowiecki, K. J. and C. Castiglione (2014). Cultural participation and tourism flows: An empirical investigation of Italian provinces. Tourism Economics 20(2), 241-262.

Brida, J. G., C. Dalle Nogare, and R. Scuderi (2016). Frequency of museum attendance: motivation matters. Journal of Cultural Economics 40(3), 261-283.

Buhalis, D. and R. Law (2008). Progress in information technology and tourism management: 20 years on and 10 years after the Internet-The state of eTourism research. Tourism Management 29(4), 609-623. 
Butts, C. T. (2008). network: a package for managing relational data in R. Journal of Statistical Software $24(2)$.

Casaló, L. V., C. Flavián, and M. Guinalíu (2010). Determinants of the intention to participate in firm-hosted online travel communities and effects on consumer behavioral intentions. Tourism Management 31(6), 898-911.

Cellini, R. and T. Cuccia (2013). Museum and monument attendance and tourism flow: A time series analysis approach. Applied Economics 45(24), 3473-3482.

Chung, J. Y. and D. Buhalis (2009). Information Needs in Online Social Networks. Information Technology \& Tourism 10(4), 267-281.

Cox, C., S. Burgess, C. Sellitto, and J. Buultjens (2009). The role of user-generated content in tourists' travel planning behavior. Journal of Hospitality Marketing 68 Management 18(8), $743-764$.

Cuccia, T., C. Guccio, and I. Rizzo (2016). The effects of UNESCO World Heritage List inscription on tourism destinations performance in Italian regions. Economic Modelling 53, 494-508.

Eisenhardt, K. M. and M. E. Graebner (2007). Theory building from cases: Opportunities and challenges. Academy of management journal 50(1), 25-32.

Faulkner, B., E. Fredline, M. Larson, and R. Tomljenovic (1999). A marketing analysis of Sweden's Storsjöyran musical festival. Tourism Analysis 4(3-4), 157-171.

Gergaud, O. and V. Ginsburgh (2017). Measuring the economic effects of events using Google Trends. In Enhancing Participation in the Arts in the EU, pp. 337-353. Springer.

Goodreau, S. M., J. A. Kitts, and M. Morris (2009). Birds of a feather, or friend of a friend? using exponential random graph models to investigate adolescent social networks. Demography $46(1)$, 103-125.

Guccio, C., D. Lisi, M. Martorana, and A. Mignosa (2017). On the role of cultural participation in tourism destination performance: an assessment using robust conditional efficiency approach. Journal of Cultural Economics 41(2), 129-154.

Herrero, L. C., J. Á. Sanz, A. Bedate, and M. J. del Barrio (2012). Who pays more for a cultural festival, tourists or locals? a certainty analysis of a contingent valuation application. International Journal of Tourism Research 14(5), 495-512.

Hiller, R. S. (2016). The importance of quality: How music festivals achieved commercial success. Journal of Cultural Economics 40(3), 309-334.

Hitters, E. (2007). Porto and Rotterdam as European Capitals of Culture: Toward the festivalization of urban cultural policy. Cultural tourism: Global and local perspectives, 281-301. 
Ho, C. I., M. H. Lin, and H. M. Chen (2012). Web users' behavioural patterns of tourism information search: From online to offline. Tourism Management 33(6), 1468-1482.

Huang, C. D., J. Goo, K. Nam, and C. W. Yoo (2017). Smart tourism technologies in travel planning: The role of exploration and exploitation. Information and Management 54(6), 757770 .

Hunter, D. R. and M. S. Handcock (2006). Inference in curved exponential family models for networks. Journal of Computational and Graphical Statistics 15(3), 565-583.

Janssen, S. and M. Verboord (2015). Cultural Mediators and Gatekeepers, pp. 440-446.

Jun, S.-P., H. S. Yoo, and S. Choi (2018). Ten years of research change using google trends: From the perspective of big data utilizations and applications. Technological Forecasting and Social Change 130, 69-87.

Karpińska-Krakowiak, M. et al. (2009). Festivalization of the city. contemporary examples. Lidé města $11(2), 338-350$.

Litvin, S. W., R. E. Goldsmith, and B. Pan (2008). Electronic word-of-mouth in hospitality and tourism management. Tourism Management 29(3), 458-468.

Llodrà-Riera, I., M. P. Martínez-Ruiz, A. I. Jiménez-Zarco, and A. Izquierdo-Yusta (2015). A multidimensional analysis of the information sources construct and its relevance for destination image formation. Tourism Management 48, 319-328.

María Munar, A. (2011). Tourist-created content: Rethinking destination branding. International Journal of Culture, Tourism and Hospitality Research 5(3), 291-305.

Noonan, D. S. and I. Rizzo (2017). Economics of cultural tourism: issues and perspectives. Journal of Cultural Economics 41(2), 95-107.

Padhi, S. S. and R. K. Pati (2017). Quantifying potential tourist behavior in choice of destination using Google Trends. Tourism Management Perspectives 24, 34-47.

Pan, B. and D. R. Fesenmaier (2006). Online Information Search. Vacation Planning Process. Annals of Tourism Research 33(3), 809-832.

Pan, B. and X. R. Li (2011). The long tail of destination image and online marketing. Annals of Tourism Research 38(1), 132-152.

Papathanassis, A. and F. Knolle (2011). Exploring the adoption and processing of online holiday reviews: A grounded theory approach. Tourism Management 32(2), 215-224.

Richards, G. (2007). The festivalization of society or the socialization of festivals? the case of Catalunya. Cultural tourism: Global and local perspectives, 257-280. 
Scuderi, R. and C. Dalle Nogare (2018). Mapping tourist consumption behaviour from destination card data: What do sequences of activities reveal? International Journal of Tourism Research 20(5), 554-565.

SGAE (2018). Anuario SGAE de las artes escénicas, musicales y audiovisuales. http://www.anuariossgae.com/home.html.

Stephens-Davidowitz, S. (2014). The cost of racial animus on a black candidate: Evidence using Google search data. Journal of Public Economics 118, 26-40.

Sullivan, O. and T. Katz-Gerro $(2006,12)$. The Omnivore Thesis Revisited: Voracious Cultural Consumers. European Sociological Review 23(2), 123-137.

Vecco, M. and A. Srakar (2017). Blue notes: Slovenian jazz festivals and their contribution to the economic resilience of the host cities. European Planning Studies 25(1), 107-126.

Xiang, Z., D. Wang, J. T. O'Leary, and D. R. Fesenmaier (2015). Adapting to the Internet: Trends in Travelers' Use of the Web for Trip Planning. Journal of Travel Research 54(4), 511-527.

Yang, X., B. Pan, J. A. Evans, and B. Lv (2015). Forecasting Chinese tourist volume with search engine data. Tourism Management 46, 386-397. 
Table 1: Ranking of music festivals in Spain (2018).

\begin{tabular}{lrrrlr}
\hline Festival name & Attendance $^{1}$ & Days & Concerts & Location & Since \\
\hline Arenal Sound & 300 & 6 & 98 & Burriana & 2010 \\
Medusa Sunbeach & 300 & 6 & 159 & Cullera & 2014 \\
Mad Cool & 240 & 3 & 143 & Madrid & 2016 \\
Primavera Sound & 220 & 4 & 261 & Barcelona & 2001 \\
Viña Rock & 210 & 3 & 122 & Villarobledo & 1996 \\
Rototom Sunsplash & 208 & 7 & 247 & Benicassim & 1994 \\
Festival Internacional de Benicassim & 170 & 4 & 136 & Benicassim & 1995 \\
Dreambeach & 155 & 5 & 112 & Cuevas del Almazora & 2013 \\
Weekend Beach & 140 & 4 & 140 & Torre del Mar & 2015 \\
Sónar & 126 & 3 & 138 & Barcelona & 1994 \\
\hline
\end{tabular}

${ }^{1}$ Figures in thousands for the whole duration of the event.

Table 2: Time frame of top searches (all dates refer to 2018).

\begin{tabular}{lrrrrrrrr}
\hline & \multicolumn{3}{c}{ Festival } & & \multicolumn{2}{c}{ Search queries } \\
\cline { 2 - 3 } Festival Internacional de Benicassim & Announced & Starts & Ends & & Starting & Ending \\
\cline { 2 - 3 } Primavera Sound & $24 / \mathrm{Jan}$ & $19 / \mathrm{Jul}$ & $22 / \mathrm{July}$ & & $23 / \mathrm{Jan}$ & $22 / \mathrm{Jul}$ \\
Sónar & $29 / \mathrm{Jan}$ & $28 / \mathrm{May}$ & $4 / \mathrm{June}$ & & $5 / \mathrm{Jan}$ & $4 / \mathrm{Jun}$ \\
& $25 / \mathrm{Jan}$ & $14 / \mathrm{Jun}$ & $16 / \mathrm{Jun}$ & & $23 / \mathrm{Jan}$ & $16 / \mathrm{Jun}$ \\
\hline
\end{tabular}

Table 3: Cross tabulation of nodes by categories, event and geographical scope of the search (world/spain).

\begin{tabular}{|c|c|c|c|c|c|c|}
\hline & \multicolumn{2}{|c|}{$F I B$} & \multicolumn{2}{|c|}{ Primavera Sound } & \multicolumn{2}{|c|}{ Sónar } \\
\hline & World & Spain & World & Spain & World & Spain \\
\hline Event planning & 0.04 & 0.06 & 0.04 & 0.13 & 0.06 & 0.14 \\
\hline Festival & 0.30 & 0.42 & 0.37 & 0.42 & 0.26 & 0.50 \\
\hline Leisure & 0.02 & & 0.02 & 0.03 & 0.06 & \\
\hline Media & 0.02 & 0.03 & 0.04 & 0.05 & 0.06 & 0.09 \\
\hline Miscellanea & 0.14 & 0.23 & 0.17 & 0.13 & 0.22 & 0.09 \\
\hline Music and musicians & 0.12 & 0.13 & 0.12 & 0.16 & 0.14 & 0.14 \\
\hline Travel & 0.36 & 0.13 & 0.25 & 0.08 & 0.20 & 0.05 \\
\hline
\end{tabular}


Table 4: Mechanisms driving edge formation: list of network effects and covariates.

\begin{tabular}{|c|c|c|}
\hline Mechanism & Description & Covariate \\
\hline Node attribute* & Tendency to form (out/in/any) ties & $\begin{array}{l}\text { node }(\text { oi } \varnothing) \text {. Festival } \\
\text { node(oi } \varnothing) \text {.Planning } \\
\text { node(oi } \varnothing) . \text { Travel } \\
\text { node(oi } \varnothing) . \text { Music } \\
\text { node(oi } \varnothing) . \text { Media }\end{array}$ \\
\hline Interaction effects* & Tendency homogeneous/heterogenous match & $\begin{array}{l}\text { nodematch.Festival } \\
\text { nodematch.Planning } \\
\text { nodematch.Travel } \\
\text { nodematch.Music } \\
\text { nodematch.Media }\end{array}$ \\
\hline Structural properties & $\begin{array}{l}\text { Density of network edges } \\
\text { Tendency to reciprocate } \\
\text { Edgewise shared partner distribution }\end{array}$ & $\begin{array}{l}\text { edges } \\
\text { mutual } \\
\text { gwesp }\end{array}$ \\
\hline
\end{tabular}

$\left({ }^{*}\right)$ A residual category is included. 
Table 5: Exponential random graph estimation results.

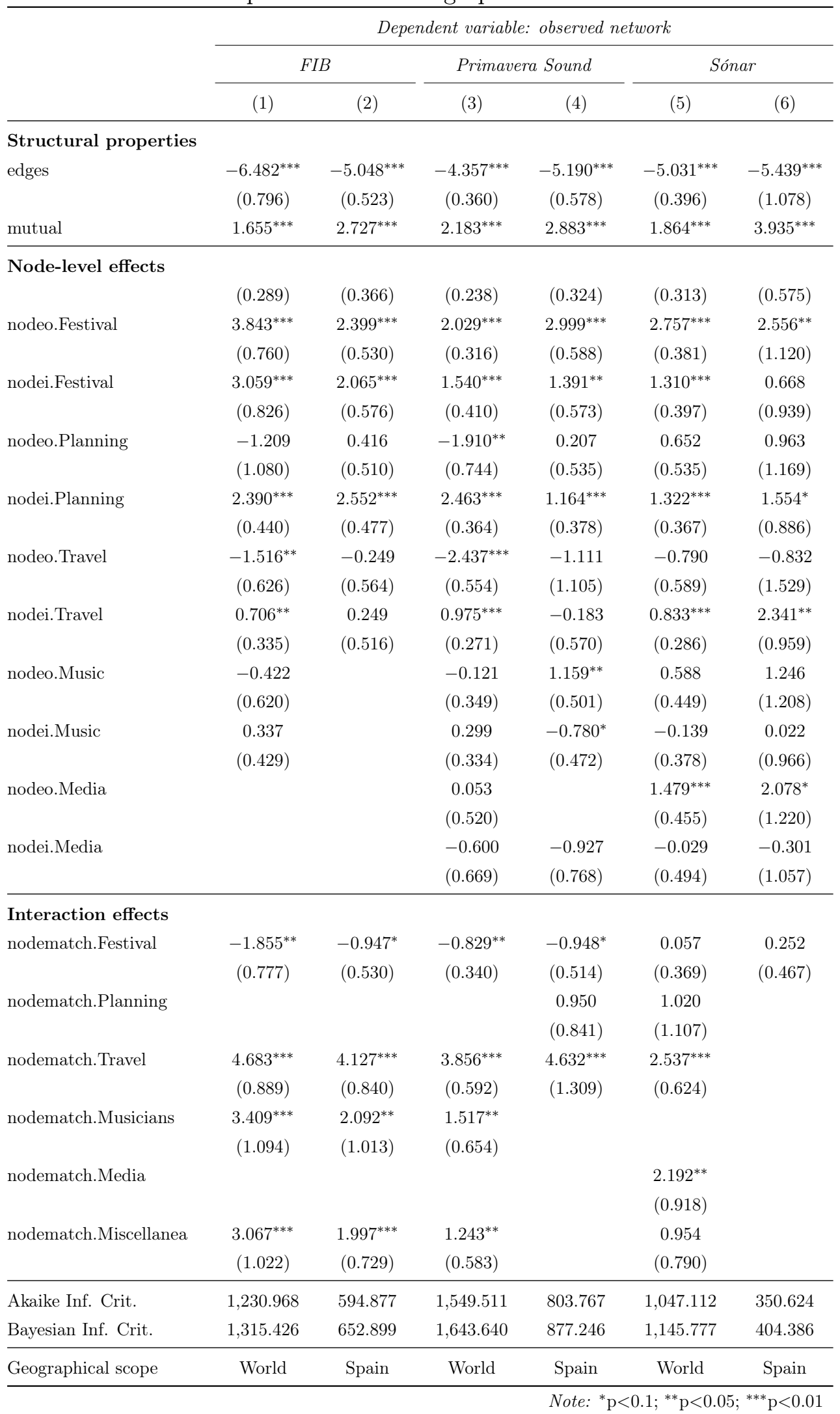


Table 6: STERGM estimation. Network formation

\begin{tabular}{|c|c|c|c|c|c|c|}
\hline & \multicolumn{6}{|c|}{ Dependent variable: observed network } \\
\hline & \multicolumn{2}{|c|}{$F I B$} & \multicolumn{2}{|c|}{ Primavera Sound } & \multicolumn{2}{|c|}{ Sónar } \\
\hline & (1) & $(2)$ & $(3)$ & (4) & $(5)$ & (6) \\
\hline \multicolumn{7}{|c|}{ Structural properties } \\
\hline edges & $\begin{array}{c}-6.689^{* * *} \\
(0.469)\end{array}$ & $\begin{array}{c}-5.807^{* * *} \\
(0.462)\end{array}$ & $\begin{array}{c}-5.731^{* * *} \\
(0.296)\end{array}$ & $\begin{array}{c}-6.709^{* * *} \\
(0.615)\end{array}$ & $\begin{array}{c}-6.086^{* * *} \\
(0.339)\end{array}$ & $\begin{array}{c}-4.702^{* * *} \\
(0.477)\end{array}$ \\
\hline mutual & $\begin{array}{c}-0.695^{*} \\
(0.408)\end{array}$ & $\begin{array}{c}1.154^{* * *} \\
(0.331)\end{array}$ & $\begin{array}{l}-0.016 \\
(0.245)\end{array}$ & $\begin{array}{c}1.019^{* * *} \\
(0.359)\end{array}$ & $\begin{array}{c}0.429 \\
(0.338)\end{array}$ & $\begin{array}{c}2.042^{* * *} \\
(0.376)\end{array}$ \\
\hline gwesp & $\begin{array}{c}0.725^{* * *} \\
(0.082) \\
\end{array}$ & $\begin{array}{c}0.398^{* * *} \\
(0.080) \\
\end{array}$ & $\begin{array}{c}0.734^{* * *} \\
(0.058) \\
\end{array}$ & $\begin{array}{c}0.482^{* * *} \\
(0.089) \\
\end{array}$ & $\begin{array}{c}0.479^{* * *} \\
(0.086)\end{array}$ & $\begin{array}{c}0.418^{* * *} \\
(0.095)\end{array}$ \\
\hline \multicolumn{7}{|l|}{ Node-level effects } \\
\hline node.Festival & $\begin{array}{c}1.846^{* * *} \\
(0.444)\end{array}$ & $\begin{array}{c}1.719^{* * *} \\
(0.453)\end{array}$ & $\begin{array}{c}1.094^{* * *} \\
(0.293)\end{array}$ & $\begin{array}{c}2.100^{* * *} \\
(0.606)\end{array}$ & $\begin{array}{c}1.511^{* * *} \\
(0.321)\end{array}$ & $\begin{array}{c}0.584 \\
(0.448)\end{array}$ \\
\hline node.Planning & $\begin{array}{l}0.831^{* *} \\
(0.360)\end{array}$ & $\begin{array}{c}0.867^{* * *} \\
(0.293)\end{array}$ & $\begin{array}{c}0.003 \\
(0.291)\end{array}$ & $\begin{array}{c}0.350 \\
(0.303)\end{array}$ & $\begin{array}{c}0.803^{* * *} \\
(0.281)\end{array}$ & $\begin{array}{l}-0.135 \\
(0.343)\end{array}$ \\
\hline node.Travel & $\begin{array}{l}-0.313 \\
(0.275)\end{array}$ & $\begin{array}{l}-0.124 \\
(0.340)\end{array}$ & $\begin{array}{l}-0.246 \\
(0.204)\end{array}$ & $\begin{array}{l}-1.017 \\
(0.742)\end{array}$ & $\begin{array}{l}-0.052 \\
(0.268)\end{array}$ & $\begin{array}{c}0.511 \\
(0.404)\end{array}$ \\
\hline node.Media & & & & & $\begin{array}{l}-0.480 \\
(0.447) \\
\end{array}$ & \\
\hline Interaction effects & & & & & & \\
\hline nodematch.Festival & $\begin{array}{c}-0.992^{*} \\
(0.532)\end{array}$ & $\begin{array}{c}-1.002^{*} \\
(0.525)\end{array}$ & $\begin{array}{c}-0.962^{* * *} \\
(0.366)\end{array}$ & $\begin{array}{c}-1.705^{* *} \\
(0.676)\end{array}$ & $\begin{array}{c}-0.829^{* *} \\
(0.420)\end{array}$ & $\begin{array}{l}-0.046 \\
(0.555)\end{array}$ \\
\hline nodematch.Planning & & & & & $\begin{array}{c}0.893 \\
(1.085)\end{array}$ & \\
\hline nodematch.Travel & $\begin{array}{c}2.569^{* * *} \\
(0.611) \\
\end{array}$ & $\begin{array}{c}4.076^{* * *} \\
(0.795) \\
\end{array}$ & $\begin{array}{c}2.617^{* * *} \\
(0.444) \\
\end{array}$ & & $\begin{array}{c}0.955 \\
(0.812)\end{array}$ & \\
\hline Akaike Inf. Crit. & $1,106.229$ & 808.223 & $1,510.928$ & 700.874 & $1,024.369$ & 500.325 \\
\hline Bayesian Inf. Crit. & $1,165.396$ & 857.471 & $1,568.699$ & 746.933 & $1,095.935$ & 538.328 \\
\hline Geographical scope & World & Spain & World & Spain & World & Spain \\
\hline
\end{tabular}


Table 7: STERGM estimation. Network dissolution

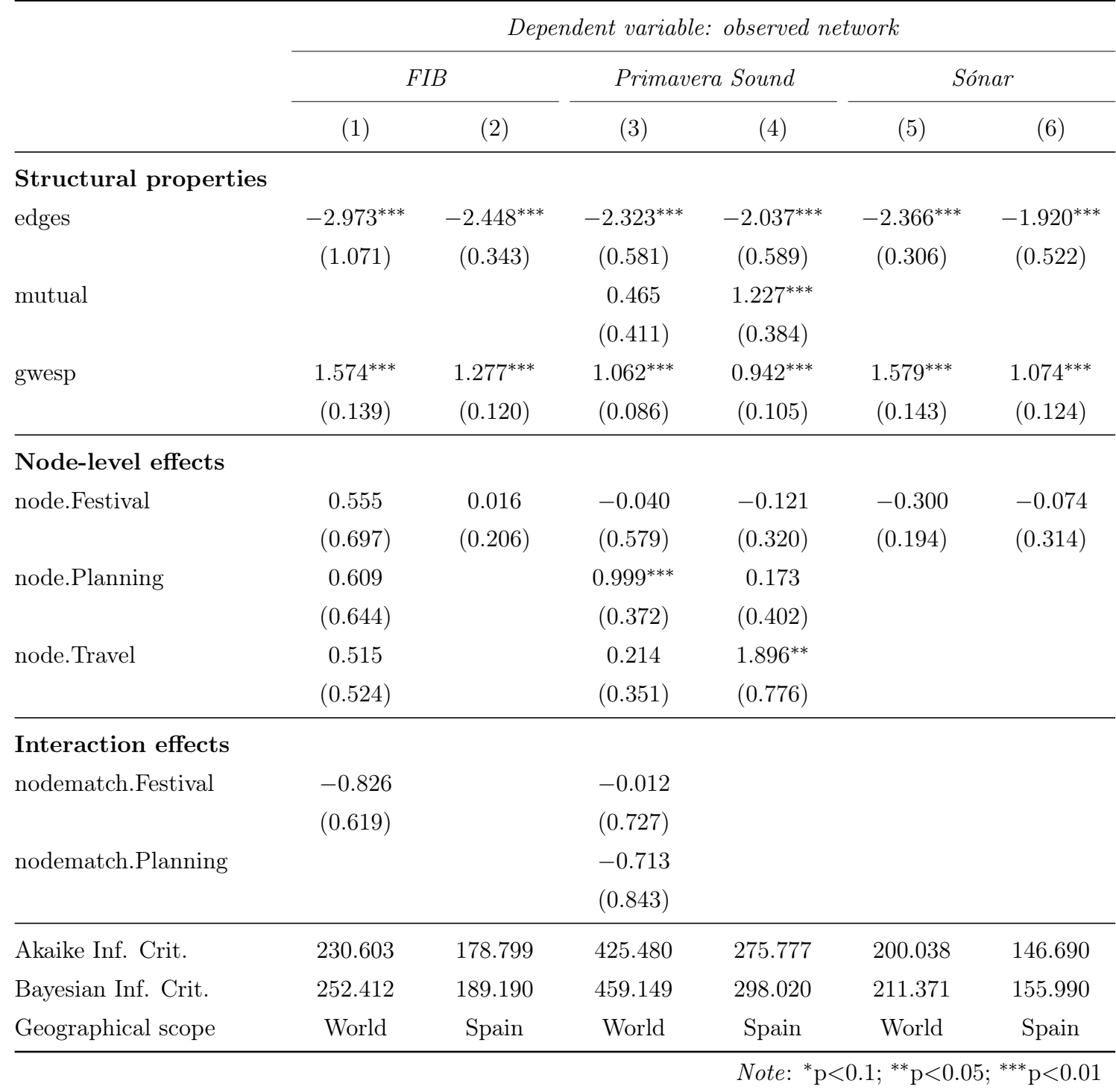




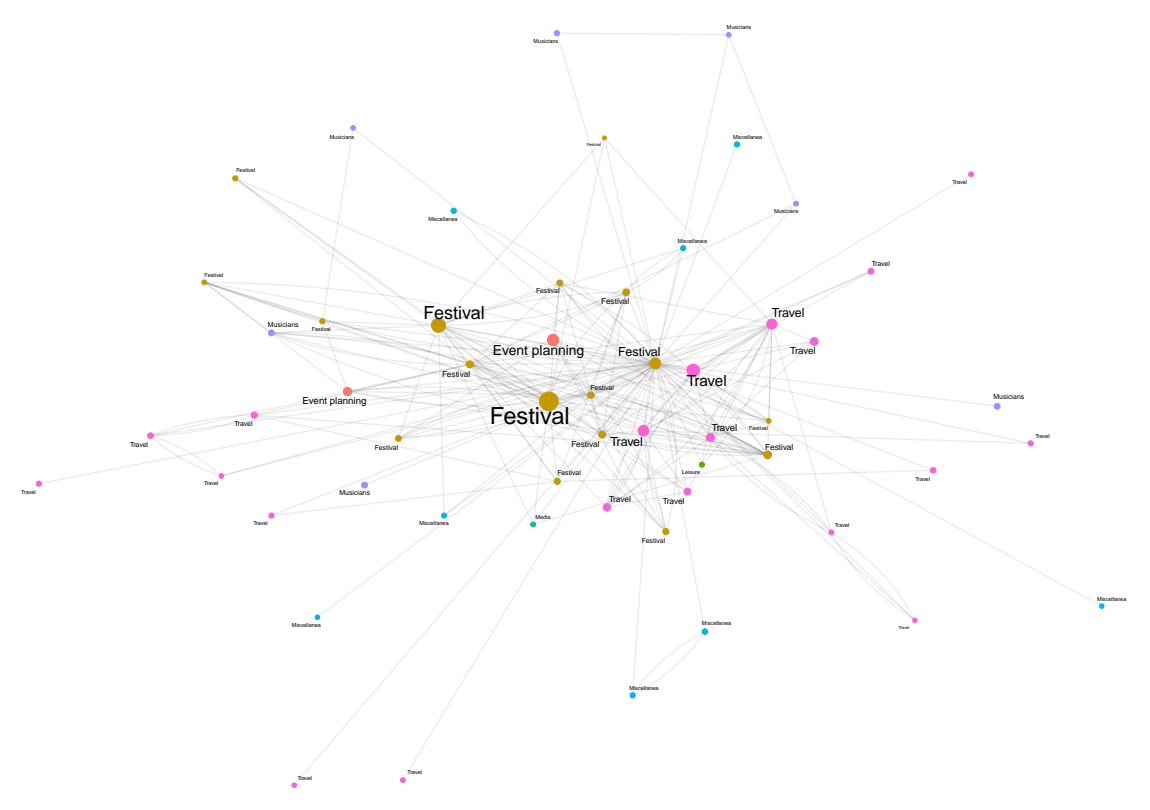

Figure 1: Network of search terms: FIB. Geographical scope of searches: World

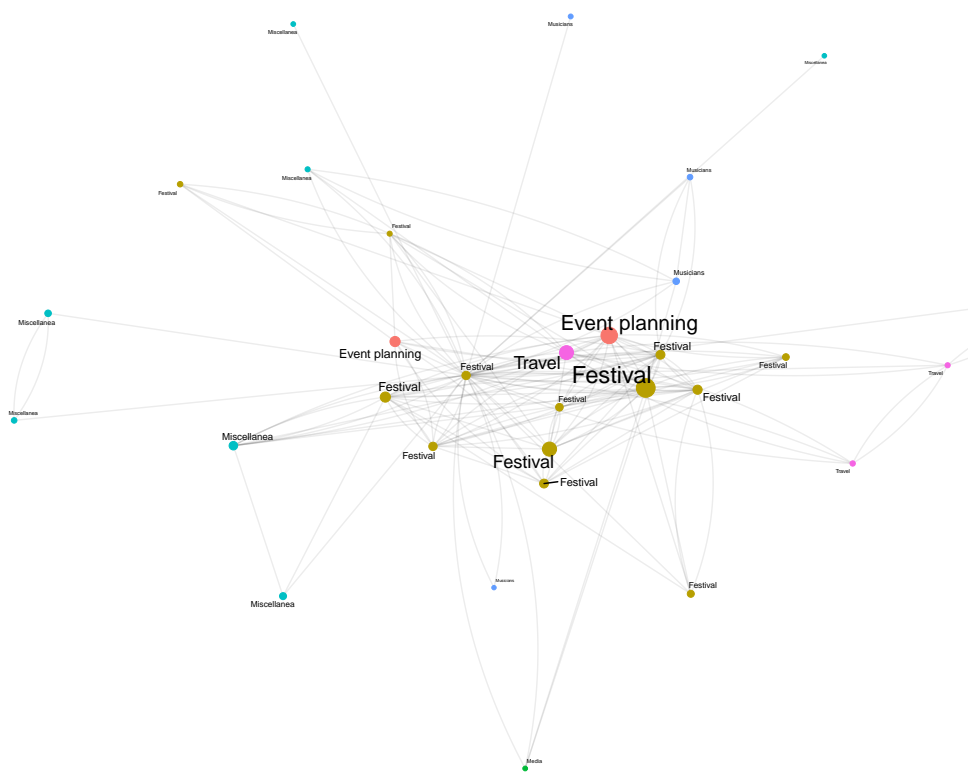

Figure 2: Network of search terms: FIB. Geographical scope of searches: Spain. 


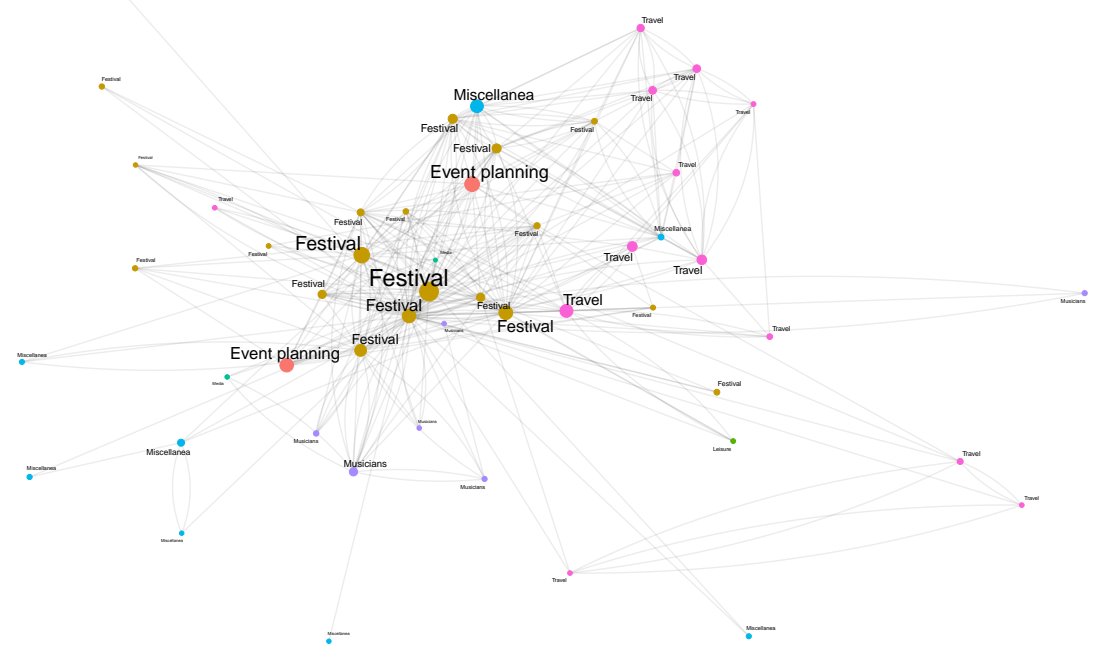

Figure 3: Network of search terms: Primavera Sound. Geographical scope of searches: World

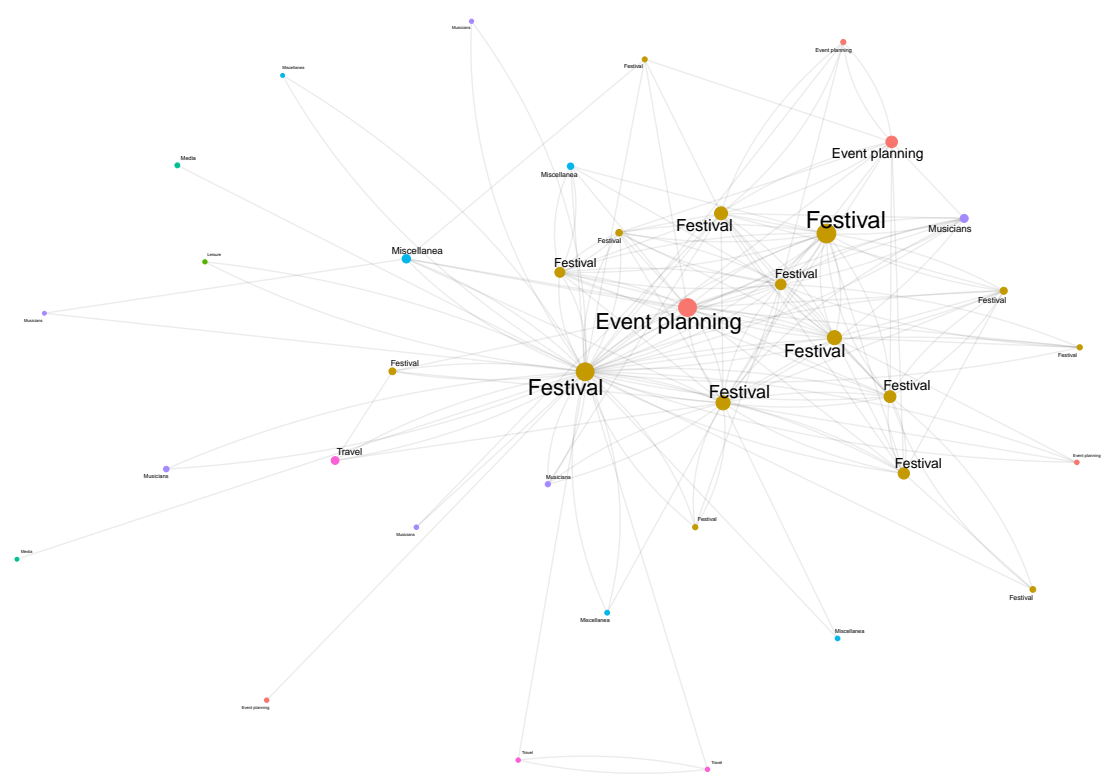

Figure 4: Network of search terms: Primavera Sound. Geographical scope of searches: Spain. 


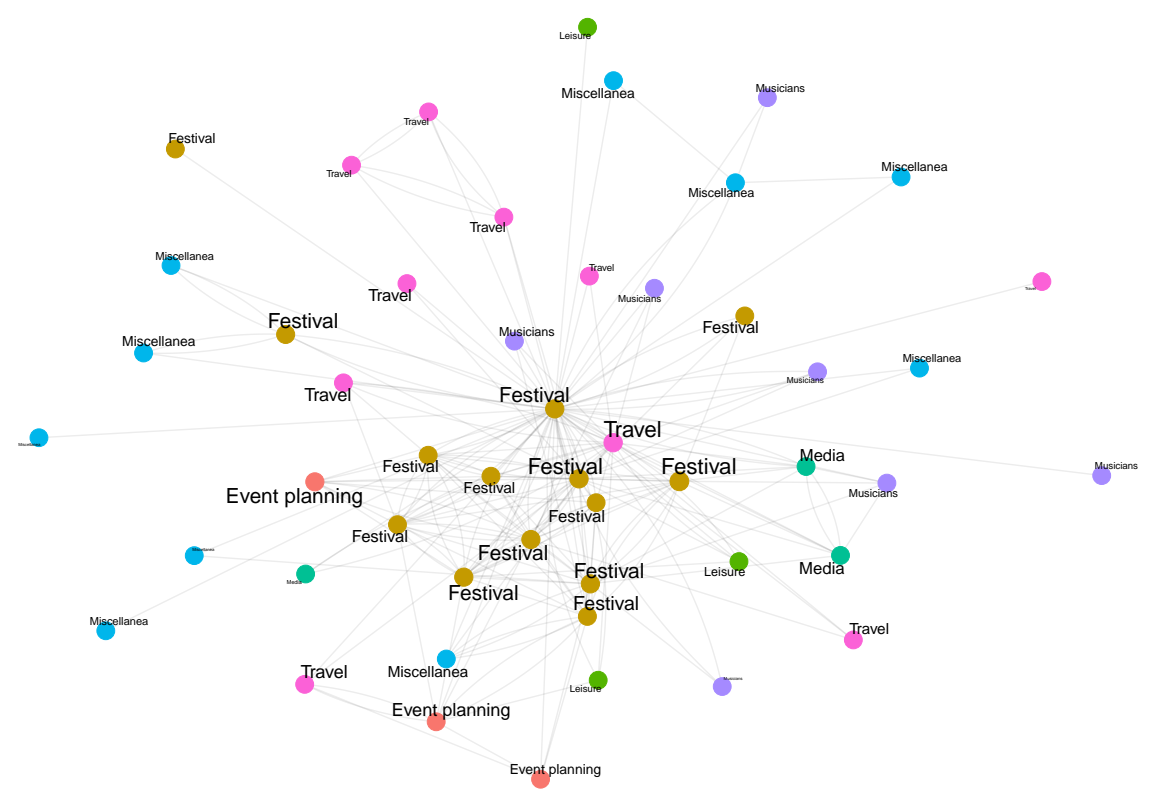

Figure 5: Network of search terms: Sónar. Geographical scope of searches: World

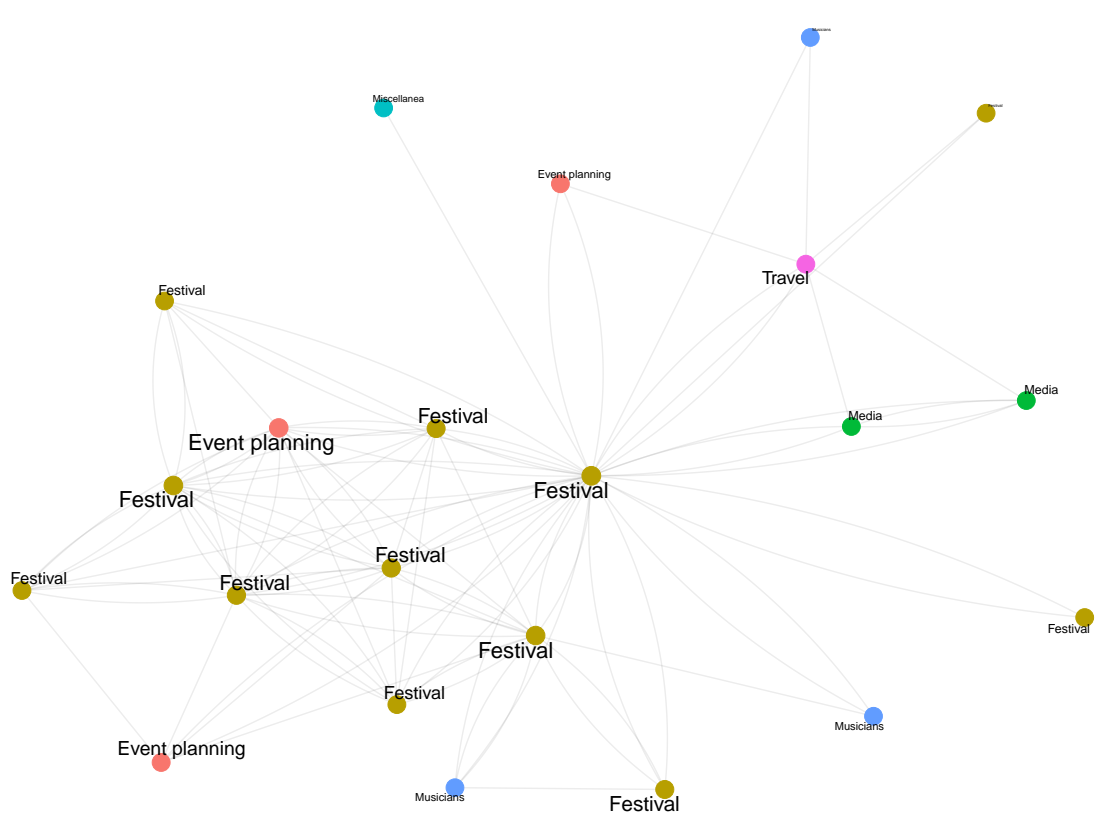

Figure 6: Network of search terms: Sónar. Geographical scope of searches: Spain. 


\section{A Dataset: list of nodes and categories}

\begin{tabular}{|c|c|c|}
\hline Node label & Google classification & Category \\
\hline 2017 Sónar June & Music Festival & Festival \\
\hline 2018 Arenal Sound Festival & Music Festival & Festival \\
\hline 2018 Sónar & Music Festival & Festival \\
\hline 2018 Sziget Festival & Music Festival & Festival \\
\hline Afterlife & Topic & Festival \\
\hline Airbnb & Company & Travel \\
\hline Airbnb & Website & Travel \\
\hline Algorithm & Topic & Musicians \\
\hline Alicante & City in Spain & Travel \\
\hline Amaia Romero & Singer & Musicians \\
\hline Arctic Monkeys & Rock band & Musicians \\
\hline Arenal Sound Festival & Music Festival & Festival \\
\hline August & Month & Miscellanea \\
\hline Azkena Rock Festival & Festival in Bilbao, Spain & Festival \\
\hline Barcelona & City in Spain & Travel \\
\hline Barcelona School of Informatics & University in Barcelona, Spain & Miscellanea \\
\hline Belle and Sebastian & Band & Musicians \\
\hline Benicàssim & Municipality in Spain & Travel \\
\hline Benidorm & City in Spain & Travel \\
\hline Berlin & Capital of Germany & Travel \\
\hline Bilbao & City in Spain & Travel \\
\hline Bilbao Bizkaia Kutxa & Bank & Miscellanea \\
\hline Bilbao Live & Music Festival & Festival \\
\hline Biletix & Topic & Event planning \\
\hline Biomimetics & Topic & Miscellanea \\
\hline Björk & Icelandic singer-songwriter & Musicians \\
\hline Budapest & Capital of Hungary & Travel \\
\hline Calendar date & Topic & Miscellanea \\
\hline Camping & Topic & Travel \\
\hline Castellón & Spanish province & Travel \\
\hline Castellón de la Plana & City in Spain & Travel \\
\hline Centre de Cultura Contemporània de Barcelona & Cultural center in Barcelona, Spain & Leisure \\
\hline Computer programming & Topic & Miscellanea \\
\hline Concert & Topic & Festival \\
\hline Concert tour & Topic & Musicians \\
\hline Croatia & Country in the Balkans & Travel \\
\hline Cruilla Barcelona & Music Festival & Festival \\
\hline DC10 & Nightclub & Leisure \\
\hline Dcode Festival & Topic & Festival \\
\hline
\end{tabular}

Continued on next page 


\begin{tabular}{|c|c|c|}
\hline Node label & Google classification & Category \\
\hline Depeche Mode & Band & Musicians \\
\hline Diynamic & Music company & Musicians \\
\hline Dream interpretation & Topic & Miscellanea \\
\hline eFestivals & Website & Media \\
\hline Euro & Currency & Travel \\
\hline Europe & Continent & Travel \\
\hline Exile & Topic & Miscellanea \\
\hline Exit & Festival & Festival \\
\hline FC Barcelona & Football club & Leisure \\
\hline Federal Bureau of Investigation & Law enforcement agency & Miscellanea \\
\hline Fertilizer & Topic & Miscellanea \\
\hline Festival & Topic & Festival \\
\hline Festival Internacional de Benicàssim & Music Festival & Festival \\
\hline Fira de Barcelona & Company & Travel \\
\hline Flight & Topic & Travel \\
\hline Glamping & Topic & Travel \\
\hline Glastonbury Festival & Music Festival & Festival \\
\hline Gorillaz & Band & Musicians \\
\hline Grand Theft Auto & Video game series & Miscellanea \\
\hline Grand Theft Auto V & Video game & Miscellanea \\
\hline Hong Kong & Chinese special administrative region & Travel \\
\hline Iceland & Country in Europe & Travel \\
\hline Icelandic language & Spoken language & Travel \\
\hline Ireland & Country in Europe & Travel \\
\hline ?stanbul & City in Turkey & Travel \\
\hline Josep Tarradellas Barcelona-El Prat Airport & Airport in Spain & Travel \\
\hline July & Month & Miscellanea \\
\hline June & Month & Miscellanea \\
\hline June 14 & Date & Miscellanea \\
\hline June 16 & Date & Miscellanea \\
\hline Killer whale & Animal & Miscellanea \\
\hline Kutxabank & Bank & Miscellanea \\
\hline La Vanguardia & Newspaper & Media \\
\hline Latitude Festival & Music Festival & Festival \\
\hline Laurent Garnier & French DJ & Musicians \\
\hline Leeds & City in England & Travel \\
\hline LIBERATO & Musical artist & Musicians \\
\hline Lisbon & Capital of Portugal & Travel \\
\hline Lollapalooza Chicago & Music Festival & Festival \\
\hline LOS40 & Radio network & Media \\
\hline LOS40 Primavera Pop & Music Festival & Festival \\
\hline
\end{tabular}

Continued on next page 


\begin{tabular}{|c|c|c|}
\hline Node label & Google classification & Category \\
\hline Low Festival & Music Festival & Festival \\
\hline Mad Cool & Topic & Festival \\
\hline Madrid & Capital of Spain & Travel \\
\hline Manchester & City in England & Travel \\
\hline Mariano Rajoy & Former Prime Minister of Spain & Miscellanea \\
\hline Marina d'Or & Topic & Travel \\
\hline Murcia & City in Spain & Travel \\
\hline Music & Topic & Musicians \\
\hline Music festival & Topic & Festival \\
\hline Musical ensemble & Topic & Musicians \\
\hline Nick Cave & Musician & Musicians \\
\hline Nina Kraviz & Russian DJ & Musicians \\
\hline NOS & Cable company & Miscellanea \\
\hline NOS Alive & Music Festival & Festival \\
\hline NOS Primavera Sound & Music Festival & Festival \\
\hline Oropesa del Mar & Municipality in Spain & Travel \\
\hline Pedro Sánchez & Prime Minister of Spain & Miscellanea \\
\hline Pet Shop Boys & Pop duo & Musicians \\
\hline Pitchfork & Topic & Media \\
\hline Poble Espanyol & Museum in Barcelona, Spain & Event planning \\
\hline Polytechnic University of Catalonia & University in Barcelona, Spain & Miscellanea \\
\hline Porto & City in Portugal & Travel \\
\hline Portugal & Country & Travel \\
\hline Portuguese Language & Spoken language & Travel \\
\hline Portuguese people & Ethnic group & Travel \\
\hline Poster & Topic & Event planning \\
\hline Pound sterling & Currency & Travel \\
\hline Primavera & Software & Miscellanea \\
\hline Primavera Sound & Music festival & Festival \\
\hline Primavera Sound Barcelona 2018 & Music Festival & Festival \\
\hline Radar & Topic & Leisure \\
\hline Radio 3 & Spanish radio station & Media \\
\hline Reading and Leeds Festivals & Music Festival & Festival \\
\hline Resident Advisor & Website & Media \\
\hline Resident Advisor Ltd. & Company & Media \\
\hline Reykjavík & Capital of Iceland & Travel \\
\hline Richie Hawtin & Electronic musician & Musicians \\
\hline Robot & Topic & Miscellanea \\
\hline Rock & Musical genre & Musicians \\
\hline Rosalía & Singer & Musicians \\
\hline Roskilde & City in Denmark & Travel \\
\hline
\end{tabular}

Continued on next page 


\begin{tabular}{|c|c|c|}
\hline Node label & Google classification & Category \\
\hline Rototom Sunsplash & Music Festival & Festival \\
\hline Rototom Sunsplash 2018 & Music Festival & Festival \\
\hline Rumor & Topic & Festival \\
\hline Ryanair & Airline & Travel \\
\hline Safe & Television series & Media \\
\hline Set list & Topic & Musicians \\
\hline Skyscanner & Website & Travel \\
\hline Skyscanner Ltd & Company & Travel \\
\hline Sonar & Topic & Festival \\
\hline Sónar & Music Festival & Festival \\
\hline SonarQube & Topic & Miscellanea \\
\hline Sound & Topic & Miscellanea \\
\hline Spain & Country in Europe & Travel \\
\hline Spring & Season & Miscellanea \\
\hline Stage & Theatre & Event planning \\
\hline Summer & Topic & Miscellanea \\
\hline Super Bock & Brand of beer & Miscellanea \\
\hline Super Bock Super Rock & Music Festival & Festival \\
\hline Sziget Festival & Music Festival & Festival \\
\hline Techno & Musical style & Musicians \\
\hline Tent & Topic & Travel \\
\hline The Killers & Rock band & Musicians \\
\hline The National & Band & Musicians \\
\hline Ticket & Admission & Event planning \\
\hline Ticketmaster & Entertainment company & Event planning \\
\hline TicketSwap & Event ticket seller in Amsterdam, Netherlands & Event planning \\
\hline Tomorrowland & Festival & Festival \\
\hline Travis Scott & American rapper & Musicians \\
\hline TRNSMT Festival & Music Festival & Festival \\
\hline Ultrasound & Diagnostic test & Miscellanea \\
\hline Valencia & City in Spain & Travel \\
\hline Volunteering & Topic & Miscellanea \\
\hline Wednesday & Day of week & Miscellanea \\
\hline Week & Unit of time & Miscellanea \\
\hline Yung Beef & Musical artist & Musicians \\
\hline
\end{tabular}

